\title{
Delirium as a complication of the surgical intensive care
}

\author{
This article was published in the following Dove Press journal: \\ Neuropsychiatric Disease and Treatment \\ 22 September 2016 \\ Number of times this article has been viewed
}

\section{Rostislav Horacek' \\ Barbora Krnacova ${ }^{2}$ \\ Jan Prasko ${ }^{2}$ \\ Klara Latalova ${ }^{2}$ \\ 'Department of Central Intensive Care Unit for Surgery, ${ }^{2}$ Department of Psychiatry, Faculty of Medicine and Dentistry, University Hospital Olomouc, Palacky University Olomouc, Czech Republic}

Background: The aim of this study was to examine the impact of somatic illnesses, electrolyte imbalance, red blood cell count, hypotension, and antipsychotic and opioid treatment on the duration of delirium in Central Intensive Care Unit for Surgery.

Patients and methods: Patients who were admitted to the Department of Central Intensive Care Unit for Surgery in the University Hospital Olomouc from February 2004 to November 2008 were evaluated using Riker sedation-agitation scale. Their blood pressure, heart rate, respiratory rate, and peripheral blood oxygen saturation were measured continually, and body temperature was monitored once in an hour. The laboratory blood tests including sodium, potassium, chlorides, phosphorus, urea and creatinine, hemoglobin, hematocrit, red and white blood cell count, and C-reactive protein, albumin levels and laboratory markers of renal and liver dysfunction were done every day. All measurements were made at least for ten consecutive days or longer until the delirium resolved.

Results: The sample consisted of 140 consecutive delirious patients with a mean age of $68.21 \pm 12.07$ years. Delirium was diagnosed in 140 of 5,642 patients $(2.48 \%)$ admitted in CICUS in the last 5 years. The median duration of delirium was 48 hours with a range of 12-240 hours. Statistical analysis showed that hyperactive subtype of delirium and treatment with antipsychotics were associated with prolonged delirium duration (hyperactive $76.15 \pm 40.53$ hours, hypoactive $54.46 \pm 28.44$ hours, mixed $61.22 \pm 37.86$ hours; Kruskal-Wallis test: $8.022 ; P<0.05)$. The duration of delirium was significantly correlated also with blood potassium levels (Pearson's $r=0.2189, P<0.05$ ), hypotension (hypotension $40.41 \pm 30.23$ hours versus normotension $70.47 \pm 54.98$ hours; Mann-Whitney $U=1,512 ; P<0.05$ ), administration of antipsychotics compared to other drugs (antipsychotics $72.83 \pm 40.6$, benzodiazepines $42.00 \pm 20.78$, others drugs, mostly piracetam $46.96 \pm 18.42$ hours; Kruskal-Wallis test: 17.39 , $P<0.0005$ ), and history of alcohol abuse (with a history of abuse $73.63 \pm 45.20$ hours, without a history of abuse $59.54 \pm 30.61$ hours; Mann-Whitney $U=1,840 ; P<0.05$ ). One patient had suffered from complicated postoperative hypostatic pneumonia and died due to respiratory failure (patient with hypoactive subtype). According to the backward stepwise multiple regression, the best significant predictors of duration of the delirium were the hypotension, type of psychopharmacs, type of delirium, the daily dose of opioids, a combination of psychopharmacs, history of alcohol abuse, plasma level of potassium, anemia, hyperpyrexia, and plasma level of albumin, reaching statistical significance (analysis of variance: $F=5.205 ; d f=24 ; P<0.005$; adjusted $r^{2}=0.637$ ).

Conclusion: The hyperactive type of delirium, hypotension, usage of antipsychotics, the higher daily dose of opioids, a combination of psychopharmacs, history of alcohol abuse, low blood levels of potassium, anemia, hyperpyrexia, and hypoalbuminemia in the CICUS were associated with longer duration of delirium.

Keywords: delirium, care duration, intensive care, risk factors, treatment, antipsychotics 


\section{Introduction}

Delirium is an acute or subacute, usually reversible syndrome of impaired higher cortical functions characterized by generalized cognitive disturbance and behavioral problems. The key clinical manifestation of delirium is a rapid change in quality of consciousness and cognition in a short time. Specifically, an excess of dopamine or depletion of acetylcholine has been associated with delirium. ${ }^{1-4}$ Moreover, central nervous system regulation, changes in a peripheral fluid, electrolyte homeostasis, and functional cardiovascular abnormalities can accompany and modify clinical symptoms of delirium. ${ }^{5,6}$

Studies conducted in various medical and surgical inpatients have demonstrated that $15 \%-70 \%$ of subjects experienced delirium at some point during their hospital stay. ${ }^{7-9}$ Reported prevalence among acute intensive care unit (ICU) is even higher, between $78 \%$ and $87 \%$ of patients, especially in elderly. ${ }^{8,10-12}$ Many individuals with this condition would be expected to have improvement in their symptoms with specific treatment of the medical conditions that likely led to the onset of delirium. ${ }^{13,14}$ Nearly one-third of patients admitted to ICU develop delirium. ${ }^{15}$ These patients are at increased risk of death during admission, longer stays in hospital, and cognitive impairment after discharge. ${ }^{15}$

\section{Risk factors}

Despite the fact that delirium is a very common problem, prospective studies examining the risk factors have been performed relatively rarely. Nevertheless, several studies, reviews, and meta-analyses have examined the risk factors for delirium in the ICU in the last 5 years. ${ }^{6,16-24}$ These investigations indicate that older age, the severity of somatic illness, hypertension, alcoholism, dementia, increased volume load during surgery, risk of infection, sensory impairment, urinary catheterization, electrolyte imbalance, malnutrition, low albumin level, use of analgesics or sedatives are associated with increased risk of delirium. Delirium is independently associated with several serious adverse outcomes including increased morbidity, mortality, likelihood of discharge to a nursing home, longer length of ICU and hospital stays, and higher medical costs. ${ }^{16,18,22-30}$ Delirium is a predictor of 6-month mortality in cases of patients who are mechanically ventilated.$^{30}$ Delirium is experienced as distress by patients, their caregivers, and nursing staff also. ${ }^{31}$ Patients admitted to an ICU have many nonmodifiable risk factors for delirium such as age, severity of physical illness, and dementia. Alcohol abuse, other illicit drugs, and use of psychoactive medication are the potentially modifiable risk factors for delirium.

\section{Duration of delirium in ICU}

Some investigations have examined the length of delirium in ICU. ${ }^{32-34}$ Patients with longer ICU stays have increased risks for acquiring nosocomial infections and other ICU-related complication factors for delirium. ${ }^{35}$ Reducing delirium duration is a critical issue in the assessment of the effectiveness of any delirium intervention. Observational studies have shown that delirium is frequently a transient syndrome with the rapid treatment of precipitating medical illness. Several studies have found that delirium in postoperative populations lasted between 1 day and 4 days in most cases. ${ }^{36-42}$ Other studies have found a more protracted course of delirium, especially in cancer populations ${ }^{40,43}$ and elderly. ${ }^{44,45}$

\section{The role of psychoactive medication in the treatment of delirium}

Psychoactive medications are used in managing the majority of delirium cases as confirmed by surveys of psychiatrist and intensive care physicians. ${ }^{46,47}$ The most frequently used drugs are the typical antipsychotics: haloperidol, tiapride, melperone; second-generation antipsychotics; benzodiazepines; or clomethiazole in the case of alcohol withdrawal delirium..$^{30,42,46,48-50}$ Although several studies have found that exposure to psychoactive medications, including antipsychotics, poses a risk for the subsequent development of delirium; on the other side, many of these studies did not establish the crucial relationship between delirium onset and use of antipsychotics. ${ }^{36,42,50-52}$ Pisani et $\mathrm{al}^{53}$ had shown that receipt of benzodiazepines before ICU admission was associated with delirium within the first 48 hours of ICU admission. Researchers have also found the use of these medications as a risk factor for transitioning to delirium. ${ }^{17}$

With regard to efficiency of individual antipsychotics, comparison trials had not identified any particular antipsychotic medication as superior to another. ${ }^{50}$ The observed improvements in delirium severity tended to occur within the first week of treatment using conservative dosing strategies. ${ }^{54}$ In a retrospective study of delirium in cancer patients, Olofsson et a ${ }^{43}$ described that patients who received haloperidol had a shorter duration of delirium compared with those who did not. In contrast, a prospective study by Manos and $\mathrm{Wu}^{55}$ and also a meta-analysis by Neufeld et $\mathrm{al}^{42}$ found that the length of delirium was significantly longer in persons referred for psychiatric consultation when they were treated with haloperidol as compared with those who did not. In a retrospective study in ICU, Milbrandt et a ${ }^{56}$ reported that patients who received haloperidol had significantly reduced mortality over those who did not. In contrast, the other 
study ${ }^{57}$ showed no significant difference in the incidence of postoperative delirium low-dose preoperative and postoperative haloperidol treatment to prevent delirium in elderly hip surgery patients.

\section{Types of delirium}

It has been shown that hyperactive delirium may be associated with a better prognosis than hypoactive delirium..$^{28,44,58}$ Individuals with hyperactive delirium are also more likely to receive antipsychotic medications. ${ }^{59}$ Hyperactive delirium may get patients at higher risk for adverse events due to disruptive behaviors such as combativeness, wandering, and other behaviors that interfere with medical care such as restlessness and agitation ending in patients manipulating with the endotracheal tubes, intravenous lines, etc.

\section{Aim of the study}

The purpose of this study was to examine the impact of the type of delirium, its possible causative factors, electrolyte imbalance, medication, physical comorbidities, such as anemia, hypotension, and more of other cofactors on the duration of Central Intensive Care Unit for Surgery (CICUS) delirium. The aim of this study was to identify which characteristics are most strongly associated with duration of delirium.

According to the hypotheses, there might be differences between duration of delirium related to 1) demographic data, eg, age and sex; 2) subtypes of delirium: hyperactive, hypoactive, mixed; 3) history of alcohol abuse; 4) patients with cancer versus patients without cancer; 5) hyperthermia; 6) hypoalbuminemia; 7) circulatory and pulmonary dysfunction (failure); 8) type of psychoactive medication; and 9) electrolyte imbalance.

\section{Patients and methods}

Study participants were 140 consecutive delirious patients (mean age: $68.21 \pm 12.07$ years, $71.4 \%$ males) admitted to the Department of Central Intensive Care Unit for Surgery in the University Hospital Olomouc from February 2004 to November 2008. More than $90 \%$ of all patients were admitted after major elective surgery. They were selected according to the complexity of complications during surgery or according to the severity of their comorbidities. Only a less number of patients were admitted after acute surgery. Some of the patients (after a complicated surgery or those with severe medical history) were mechanically ventilated or planned for delayed extubation postoperatively. Others received oxygen supplementation by the face mask. The blood pressure (IBP or NIBP), heart rate, respiratory rate, peripheral oxygen saturation, and body temperature were monitored continuously. The analgesics (mostly opiates), fluid therapy, and other intravenous drugs were administered. Complex laboratory tests including bedside blood gasses analysis were available, and all disturbances present were corrected immediately. The Glasgow Coma Scale, Sepsis-related Organ Failure Assessment Score, and Acute Physiology and Chronic Health Evaluation II scores were recorded in all the patients admitted in SICU, and the Riker sedation-agitation scale (Riker SAS) and Richmond agitation-sedation scale (RASS) were used in patients with psychiatric history, neurological alterations, with disorientation or patients with delirium.

Of 5,642 admitted patients, a total of 203 patients were diagnosed with severe delirium, and finally, 140 patients met the inclusion criteria and were enrolled in the study. In this study, the cut point for enrollment was at least 12 hours of duration of the delirium. Of the 63 nonenrolled patients, 51 patients did not complete the criterion of minimum time in the CICUS, 12 patients were excluded from further analysis due to the persistently low level of consciousness or coma. One patient died $(0.71 \%)$. Informed consent had been acquired from the patients just before the surgery at the time of admission to the University Hospital Olomouc. Second consent was obtained after the delirium subsided and according to consent consensus approved by the University Hospital Olomouc Committee.

\section{Assessment}

Medical records were studied to get an admitting diagnosis. The components of routine laboratory measurements that were examined included body temperature, mean blood pressure, heart rate, respiratory rate, serum sodium level, potassium level, chlorides, creatinine level, full blood count, white blood cell count, C-reactive protein (CRP), phosphorus, proteins, albumin, and laboratory markers of renal and liver dysfunction. Clinically meaningful thresholds were used to categorize physiological variables as abnormal, and these cut points are presented in Table 1.

The status of the patient was evaluated by the physicians three times a day. Nurses performed the chart scales, monitored the clinical state of the patients, and recorded administrated medication.

Delirium was assessed using the validated chart review methods four times a day (every 6 hours). The physicians made the initial diagnosis according to the clinical picture of the patient and Riker SAS and RASS were used as additional tools for confirming the diagnosis. The outcome - variable 
Table I Laboratory markers

\begin{tabular}{|c|c|c|c|c|c|}
\hline Variable & Physiological range & $\begin{array}{l}\text { Number } \\
\text { of patients }\end{array}$ & $\begin{array}{l}\text { Number of } \\
\text { patients below } \\
\text { the threshold/ } \\
\% \text { of patients }\end{array}$ & $\begin{array}{l}\text { Number of } \\
\text { patients in } \\
\text { normal range/\% } \\
\text { of patients }\end{array}$ & $\begin{array}{l}\text { Number of } \\
\text { patients above } \\
\text { the threshold/ } \\
\% \text { of patients }\end{array}$ \\
\hline Anemia by ERY & ERY $4.0-5.80 \times 10^{-12}$ & 140 & $122 / 87.14$ & $18 / 12.86$ & $0 / 0$ \\
\hline Anemia in study $\mathrm{Hb}$ in $\mathrm{g} / \mathrm{L}$ & $\mathrm{Hb}<120 \mathrm{~g} / \mathrm{L}$ & 140 & $122 / 87.14$ & $18 / 12.86$ & $0 / 0$ \\
\hline $\begin{array}{l}\text { Peripheral patients body } \\
\text { temperature/axillary }\end{array}$ & $\begin{array}{l}\text { Body temperature: } 35.5^{\circ} \mathrm{C}-38.0^{\circ} \mathrm{C} \\
\text { Hyperthermia }>38.0^{\circ} \mathrm{C}\end{array}$ & 140 & $22 / 15.71$ & 99/70.7I & $19 / 13.59$ \\
\hline CRP & $0-10.0 \mathrm{mg} / \mathrm{L}$ & 63 & 0 & 0 & $63 / 100$ \\
\hline Hypotension & MAP $<65$ Torr (IBP) & 140 & $44 / 31.43$ & $96 / 68.57$ & $0 / 0$ \\
\hline Sodium & |30-144 mmolL & 135 & $|0 / 7.4|$ & II8/87.4| & $7 / 5.19$ \\
\hline Potassium & $3.6-5.4 \mathrm{mmol} / \mathrm{L}$ & 134 & $14 / 10.45$ & || $7 / 87.3 \mid$ & $3 / 2.24$ \\
\hline Phosphates & $0.8-1.6 \mathrm{mmol} / \mathrm{L}$ & 64 & $22 / 34.38$ & $36 / 56.25$ & $6 / 9.38$ \\
\hline Chlorides & $95-110 \mathrm{mmol} / \mathrm{L}$ & 135 & $2 / 1.48$ & $122 / 90.37$ & $11 / 8.15$ \\
\hline Proteinemia & $65.0-85.0 \mathrm{~g} / \mathrm{L}$ & 50 & $47 / 94$ & $3 / 6$ & $0 / 0$ \\
\hline Albuminemia & $35.0-50.0 \mathrm{~g} / \mathrm{L}$ & 48 & $44 / 91.67$ & $4 / 8.33$ & $0 / 0$ \\
\hline
\end{tabular}

Abbreviations: $\mathrm{Hb}$, hemoglobin; CRP, C-reactive protein; ERY, erythrocytes number; MAP, minimal arterial pressure; IBP, invasive blood pressure.

duration of delirium - was the length of the delirium measured in hours. Delirium was defined as a sequence of consecutive hours of delirium as assessed by the chart review. Likewise, if a nondelirium or coma day occurred in between delirium days, the nondelirium day was included in the delirium episode. Each studied episode ended when there were 48 consecutive hours without delirium.

The predictor variables such as types of delirium, primary somatic disorder, complications, electrolytes imbalance, anemia, hypoproteinemia, hypotension, age, sex, cancer, alcohol, nicotine or illicit drugs dependence, and type of used psychoactive medication were correlated with the duration of delirium. Cut points corresponded with the physiological range (Table 1).

\section{Treatment approaches}

The attending physician carried choice of the drugs. All types, dosages, and routes of administration of medication were recorded.

\section{Statistics}

Statistics were calculated using GraphPad Prism 5.0 and SPSS 24. Demographic and clinical characteristics were analyzed using descriptive statistics. Normal distribution of the demographic and clinical variables was determined by the Shapiro-Wilk $W$-test. The $\chi^{2}$ test or Fisher's exact test was used for the analyses of categorical data. Relationships between variables were examined by Pearson's or Spearman's correlation coefficient and backward stepwise multiple regression. Bonferroni correction was added to the regression to lower the probability of false-positive results. The effect of size of the multiple linear regression analysis was calculated using the $\mathrm{f} 2$ indicator or its equivalents. The statistical significance threshold was set at $5 \%$.

\section{Results \\ Demography}

Characteristics of the study population are presented in Table 2. The mean age of the participants was $68.21 \pm 12.07$ years. A total of $71.4 \%$ of patients were male. The median duration of SICU delirium was 48 hours, with a range of 12-240 hours and mean duration of $65.61 \pm 38.09$ hours. One patient died $(0.71 \%)$. (A 61-year-old male, who was presented with alcohol-withdrawal delirium, after transfer to another department, in who respiratory distress emerged, died of respiratory failure.)

\section{The drug data}

The drug data for this study are presented in Table 3. The majority of patients received the antipsychotics (72.1\%), benzodiazepines ( $8.6 \%$ ), piracetam, and few of them other types of medications such as clonidine and citalopram (17.9\%). Eight patients were treated with propofol together with an opioid. The majority of patients received just one of the drugs, as a monotherapy, not a combination of them. However, 44 patients had some type of a drug combination, nine (midazolam and tiapride), two (clonazepam and tiapride), five (propofol and tiapride), three (propofol and haloperidol), nine (piracetam and tiapride), seven (diazepam and tiapride), five (clonidine and tiapride), one (alprazolam and tiapride), one (olanzapine and tiapride), one (haloperidol and tiapride), and one (melperone and haloperidol). Reasons for combinations were a high degree of agitation or the necessity of a mechanical restriction. Two patients switched from 
Table 2 Main demographic and clinical data

\begin{tabular}{|c|c|}
\hline Age (years) & $68.21 \pm 12.07$ \\
\hline Sex: female:male & $40: 100$ \\
\hline Preexisting psychiatric diagnosis, n (\%) & $20(14.3)$ \\
\hline \multicolumn{2}{|l|}{ Somatic diseases, n (\%) } \\
\hline Cancer & $86(6 \mid .4)$ \\
\hline Alcohol abuse & $29(20.7)$ \\
\hline Other dependency & $27(19.3)$ \\
\hline Heart failure & $9(6.4)$ \\
\hline Lung failure & $28(20)$ \\
\hline Liver failure & $4(2.9)$ \\
\hline Kidney failure & I $(0.7 \mathrm{I})$ \\
\hline Polytrauma & $5(3.6)$ \\
\hline Head injury & $6(4.3)$ \\
\hline Hyperpyrexia $\left(>38^{\circ} \mathrm{C}\right)$ & $19(13.6)$ \\
\hline Anemia (defined as hemoglobin $<120 \mathrm{~g} / \mathrm{L}$ ) & $122(87.1)$ \\
\hline $\begin{array}{l}\text { Hypotension (medium arterial } \\
\text { pressure }<70 \text { Torr) }\end{array}$ & $44(31.4)$ \\
\hline Hypoproteinemia (<65 g/L) & $48(34.3)$ \\
\hline \multicolumn{2}{|l|}{ Number of patients and mean dosage of: } \\
\hline $\begin{array}{l}\text { Benzodiazepines (in milligram of } \\
\text { diazepam) }\end{array}$ & $12(35.83)$ \\
\hline $\begin{array}{l}\text { Opioids (mean index in milligram } \\
\text { of morphine) }\end{array}$ & $108(39.30)$ \\
\hline $\begin{array}{l}\text { Antipsychotics (in milligram } \\
\text { of haloperidol) }\end{array}$ & I0I (I2.03) \\
\hline Propofol & $\begin{array}{l}8 \text { (continuous infusion, } \\
\text { average } 1,000 \mathrm{mg} \text { daily) }\end{array}$ \\
\hline \multicolumn{2}{|l|}{ Subtypes of delirium, n (\%) } \\
\hline Hyperactive & $54(38.6)$ \\
\hline Hypoactive & $27(19.3)$ \\
\hline Mixed & $59(42.1)$ \\
\hline
\end{tabular}

benzodiazepines to antipsychotics due to increased risk of a respiratory problem. The opioids used in 111 patients, are more questionable, because they probably contribute most to the extension of the delirium. The same can be claimed for antibiotics used in 96 patients.

Table 3 Psychoactive medication

\begin{tabular}{lll}
\hline Drug & Patients, n (\%) & Mean milligram dosage \\
\hline Tiapride & $85(60.7)$ & 589 \\
Haloperidol & $9(6.4)$ & 15.45 \\
Melperone & $5(3.6)$ & 100 \\
Olanzapine & $2(0.7)$ & 15 \\
Antipsychotics & I0I (72.1) & 11.84 (haloperidol equivalent) \\
Midazolam & $2(1.4)$ & 37.50 \\
Alprazolam & I (0.7) & 1 \\
Diazepam & $7(5)$ & 12.14 \\
Bromazepam & I (0.7) & 3 \\
Clonazepam & I (0.7) & 1.50 \\
Benzodiazepines & I2 (8.6) & 35.83 (diazepam equivalent) \\
Zolpidem & I (0.7) & 10 \\
Clonidine & $6(4.3)$ & 0.40 \\
Piracetam & I (12.1) & 2,624 \\
Citalopram & I (0.7) & 20 \\
Others & $25(17.9)$ & \\
\hline
\end{tabular}

\section{Treatment outcome}

Fully resolved delirium can be detected after 12-240 hours with a median of 48 hours and mean of $65.61 \pm 38.09$ hours. The mean duration of the delirium in females $(n=40)$ was $58.15 \pm 30.47$ hours and in males $(n=100)$ was $68.57 \pm 40.48$ hours, there were no statistical differences found (Mann-Whitney $U=1,640$ : ns).

\section{Comparison of different types of delirium}

Three clinical subtypes of delirium, based on arousal disturbance and psychomotor activity, have been described. These subtypes included the "hyperactive" (agitated) subtype, the "hypoactive" (lethargic) subtype, and a "mixed" subtype with alternating features of hyperactive and hypoactive delirium. There were statistically significant differences in the meantime for the duration of delirium according to its subtype. The average length of hyperactive subtype was $76.15 \pm 40.53$ hours, in hypoactive subtype $54.46 \pm 28.44$ hours, and in mixed subtype $61.22 \pm 37.86$ hours (Kruskal-Wallis test: $8.022 ; P<0.05$ ). Dunn's multiple comparison tests showed the difference between hyperactive and hypoactive delirium $(P<0.05)$. All the three clinical subtypes of delirium were not statistically different in other parameters such as age (hyperactive: $65.44 \pm 11.77$ years; hypoactive: $69.3 \pm 15.31$ years; mixed: $70.25 \pm 10.28$ years; one-way analysis of variance [ANOVA]: $F=2.42, d f=139 ; P=0.0927$ ), plasma CRP, potassium, chlorides, proteins, albumins (all one-way ANOVA, ns), but there was a statistical difference in the levels of phosphorus (hyperactive: $0.85 \pm 0.33$; hypoactive: $1.28 \pm 0.52$; mixed $0.88 \pm 0.33$; one-way ANOVA: $F=2.42, d f=139 ; P<0.005)$ with Tukey's Multiple Comparison Test showed differences between hypoactive delirium and both other subtypes (both: $P<0.05$ ).

\section{Comparison of different clinical conditions}

There were no statistically significant differences in the duration of delirium in patients with hyperpyrexia, carcinoma, circulatory and pulmonary failure, need for reintubation, preexisting psychiatric diagnosis, and anemia or hypoproteinemia compared with patients without these conditions (Table 4). Nevertheless, there were statistically significant differences in duration of delirium in patients with and without hypotension and with and without a history of alcohol abuse.

\section{Comparison of laboratory findings}

The duration of delirium did not correlate with the values of plasma hemoglobin (in grams per liter), CRP (in milligrams 
Table 4 Delirium duration according to complicating conditions and laboratory factors

\begin{tabular}{|c|c|c|c|c|c|c|}
\hline & \multicolumn{2}{|l|}{ Hyperpyrexia } & \multicolumn{2}{|l|}{ Hypotension } & \multicolumn{2}{|l|}{ Carcinoma } \\
\hline & No $(n=1 \mid 9)$ & Yes $(n=18)$ & No $(n=94)$ & Yes $(n=43)$ & No $(n=53)$ & Yes $(n=84)$ \\
\hline Duration \pm SD & $62.32 \pm 30.66$ hours & $87.33 \pm 67.10$ hours & $70.47 \pm 54.98$ hours & $40.4 I \pm 30.23$ hours & $66.57 \pm 37.84$ hours & $65.00 \pm 38.46$ hours \\
\hline \multirow[t]{3}{*}{ Statistics } & \multicolumn{2}{|c|}{ Mann-Whitney U=898; ns } & \multicolumn{2}{|c|}{ Mann-Whitney $U=|, 5| 2 ; \boldsymbol{P}<\mathbf{0 . 0 5}$} & \multicolumn{2}{|c|}{ Mann-Whitney U=2,156; ns } \\
\hline & \multicolumn{2}{|c|}{ Circulatory and pulmonary failure } & \multicolumn{2}{|l|}{ Reintubation } & \multicolumn{2}{|l|}{ Alcohol abuse } \\
\hline & No $(n=109)$ & Yes $(n=28)$ & No $(n=|| 8)$ & Yes $(n=19)$ & No $(n=78)$ & Yes $(n=59)$ \\
\hline Duration \pm SD & $61.32 \pm 31.38$ hours & $82.29 \pm 54.82$ hours & $64.17 \pm 36.17$ hours & $74.53 \pm 48.59$ hours & $59.54 \pm 30.61$ hours & $73.63 \pm 45.20$ hours \\
\hline \multirow[t]{3}{*}{ Statistics } & \multicolumn{2}{|c|}{ Mann-Whitney $U=I, 202 ;$ ns } & \multicolumn{2}{|c|}{ Mann-Whitney $U=I, 0 I 0$; ns } & \multicolumn{2}{|c|}{ Mann-Whitney $U=I, 840 ; P<0.05$} \\
\hline & \multicolumn{2}{|c|}{ Preexisting psychiatric diagnosis } & \multicolumn{2}{|l|}{ Anemia } & \multicolumn{2}{|l|}{ Hypoproteinemia } \\
\hline & No $(n=|| 8)$ & Yes $(n=19)$ & No $(n=18)$ & Yes (n=I19) & No $(n=90)$ & Yes $(n=47)$ \\
\hline Duration \pm SD & $64.78 \pm 35.54$ hours & $70.74 \pm 52.14$ hours & $62.00 \pm 28.59$ hours & $66.15 \pm 39.39$ hours & $64.93 \pm 36.02$ hours & $66.89 \pm 42.15$ hours \\
\hline Statistics & \multicolumn{2}{|c|}{ Mann-Whitney $U=I, I 20$; ns } & \multicolumn{2}{|c|}{ Mann-Whitney $U=I, 047$; ns } & \multicolumn{2}{|c|}{ Mann-Whitney $U=2,104$; ns } \\
\hline
\end{tabular}

Abbreviations: ns, not significant; SD, standard deviation.

per liter), sodium, phosphorus, and chloride levels (all in millimoles per liter), with proteinemia or with albuminemia (both in grams per liter). However, the duration of delirium did significantly correlate with plasma potassium levels (in milligrams per liter; Pearson's $r=0.2189, P<0.05$ ). Linear regression between plasma potassium level and duration of the delirium in hours is highly statistically significant (Figure 1).

\section{Comparison of types of psychoactive medication}

There were statistically significant differences (KruskalWallis test: $17.39, P<0.0005)$ in duration of delirium in groups treated with antipsychotics $(\mathrm{n}=101$, mean $=72.83 \pm 40.6$ hours), with benzodiazepines ( $\mathrm{n}=12$, mean $=42.00 \pm 20.78$ hours), and the group treated with other drugs $(n=23$, mean $=46.96 \pm 18.42$ hours).

For more detailed understanding, the three largest subgroups were compared according to the medication

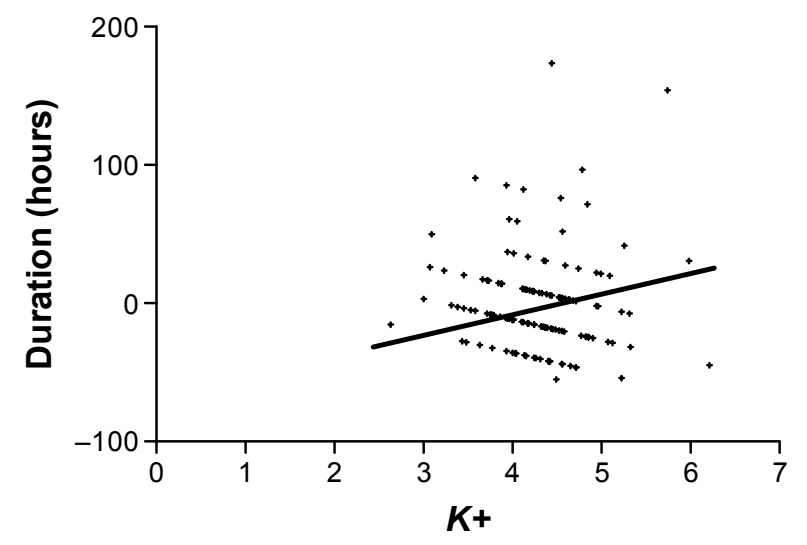

Figure I Linear regression of plasma potassium level (mmol/L) and duration of delirium (hours).

Note: Linear regression: $t=19.96, d f=130.0, P<0.0001$. (typical antipsychotics $n=99$; anxiolytics $n=13$; and piracetam $\mathrm{n}=17$ ). There was statistically significant difference (KruskalWallis: $13.27 ; P<0.005)$ in the duration of delirium in patients treated with typical antipsychotics ( $m e a n=70.67 \pm 37.00$ hours) versus anxiolytics (mean $=42.46 \pm 19.97$ hours) but not versus piracetam (mean $=49.41 \pm 19.85$ hours). The comparison of the somatic illnesses and complications and the types of delirium in these three subgroups is shown in Table 5. The group treated with anxiolytics was significantly younger than the group treated with antipsychotics. There were significantly higher numbers of patients with a hyperactive form of delirium in an antipsychotic group than in two other groups.

\section{Regression analysis}

Various factors are significantly associated with the duration of the delirium. Hence, multiple regression analyses were performed. Backward stepwise regression identified the most important factors linked to the duration of delirium as the dependent variable. The independent variables, which entered, to the regression analysis, were types of delirium, plasma potassium level, plasma chlorides level, anemia, albuminemia, hyperpyrexia, hypotension, history of alcohol abuse, hepatic failure, type of psychoactive drugs and their dosages, use of a combination of psychopharmacs, administration of antibiotics, type of delirium, the daily dosage of opioids (calculated to morphine index), and cardiopulmonary resuscitation in ICU.

The backward stepwise regression consisted of seven steps. Hypotension, type of psychopharmacs, type of delirium, the daily dosage of opioids, a combination of psychopharmacs, and alcohol abuse history, plasma potassium level, anemia values, hyperpyrexia, and albuminemia reached statistical significance. The subsequent model explained $63.7 \%$ of the dependent variable $(P<0.001$; Table 6$)$. 


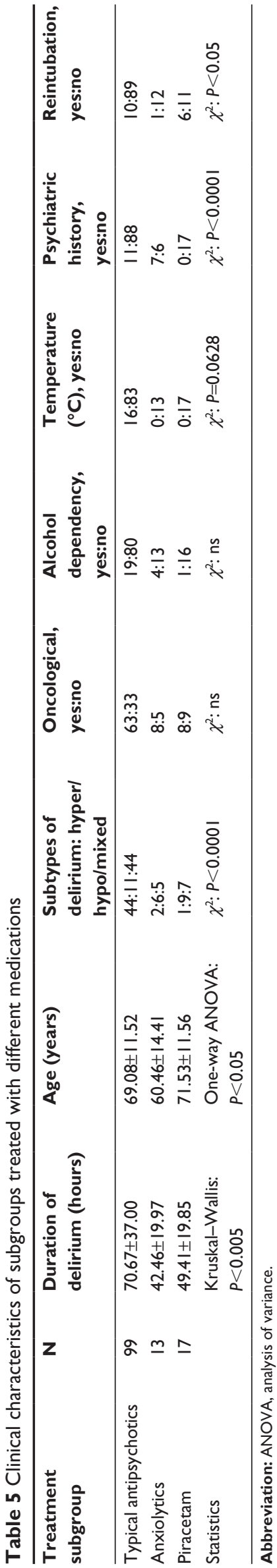

\section{Discussion}

The incidence of delirium in the ICU $(2.5 \%)$ was much less than that is usually quoted for surgical inpatient (typically between $15 \%$ and $70 \%)^{8,10-12}$ The reason for the difference between another statistic from ICU setting is unknown but could be attributed to the fact that most patients in this ICU were young people without a recent history of complicated surgery. The question is about the ICU admission criteria in different countries.

The average duration of the delirium (2-3 days) in this study corresponds with the findings reported by other ICU delirium studies..$^{27,32-34}$ One patient had died due to respiratory failure, with complicated postoperative hypostatic pneumonia (patient with hypoactive subtype). Previous studies s $^{21,60-64}$ have examined risk factors for delirium; however, this study is distinctive in focusing on factors that may influence the duration of the delirium in CICUS.

Dehydration has been documented to be a risk factor for delirium in non-ICU populations. ${ }^{60,65,66}$ In this study, dehydration was not associated with longer delirium. A previous study ${ }^{67}$ has documented that early correction of dehydration is associated with prevention of delirium. Studies in the ICUs have demonstrated that rapid and aggressive volume resuscitation can decrease mortality from sepsis, but these studies did not evaluate delirium at all. ${ }^{68}$ With the establishment of early goal-directed fluid therapy, dehydration may be less significant as a risk factor for prolonged delirium in CICUS. Several variables were significantly linked to the length of delirium, including the type of delirium (hyperactive), mean arterial pressure (hypotension), and higher potassium level and alcohol abuse history in unadjusted analysis. Higher doses of antipsychotics and the combination of psychopharmacs were connected with longer duration of delirium. The results are in agreement with the other study carried out in the psychiatric department with patients with delirium tremens. ${ }^{69}$ The longest duration of delirium was detected in the group treated with antipsychotics than in the group treated with benzodiazepines. Higher age could cause this prolongation in this group significantly. However, this explanation is insufficient to interpret statistically shorter duration of delirium in patients treated with other drugs (preferably with piracetam) and being of the same age. There may be two other explanations: antipsychotics prolonged the duration of delirium or conversely antipsychotics were administered to patients in more severe condition. In fact, in this study, benzodiazepines were not administered to elderly patients with severe somatic diseases and in the case of high risk of respiratory or cardiac failure. The data are not sufficient to answer this question. 
Table 6 Multiple regression analysis with the duration of delirium as a dependent variable

\begin{tabular}{lllllll}
\hline Model & Regressors & B & SE & $\beta$ & T & Significance \\
\hline 7 & Hypotension & 54.72 & 19.14 & 0.52 & 2.86 & 0.013 \\
& Type of psychopharmacs & 10.18 & 2.17 & 0.73 & 4.68 & 0.000 \\
& Type of delirium & -22.98 & 7.85 & -0.48 & -2.93 & 0.011 \\
& Daily dosage of opioids & 1.34 & 0.43 & 0.43 & 3.09 & 0.008 \\
& Combination of psychopharmacs & 57.94 & 13.98 & 0.60 & 4.14 & 0.001 \\
& History of alcohol abuse & 46.64 & 16.23 & 0.46 & 2.87 & 0.012 \\
& Blood levels of potassium & 37.49 & 17.09 & 0.36 & 2.19 & 0.046 \\
& Anemia & 1.30 & 0.46 & 0.44 & 2.83 & 0.014 \\
& Hyperpyrexia & 93.32 & 22.15 & 0.78 & 4.21 & 0.001 \\
& Albuminemia & 4.99 & 1.97 & 0.52 & & 2.54 \\
\end{tabular}

Notes: ANOVA: $F=5.205 ; d f=24 ; P<0.005$. Adjusted $r^{2}=0.637$.

Abbreviations: SE, standard error; ANOVA, analysis of variance.

Benzodiazepines could cause a higher risk of respiratory failure in elderly, severe somatic ill patients. So, antipsychotics were preferred to be administered to these risk patients. It is supposed that this was the reason of prolonged delirium duration in the antipsychotics group. Benzodiazepines were also used in some patients with a hypoactive subtype of delirium. These patients were intubated and artificially ventilated, so respiratory depression did not threaten.

Many factors that arise during the CICUS stay undoubtedly contributed to the development and duration of delirium. Multiple regression analysis showed that hypotension, type of psychoactive agents, type of delirium, the daily dosage of opioids, a combination of psychopharmacs, history of alcohol abuse, plasma levels of potassium, anemia, hyperpyrexia, and albuminemia contribute to the duration of delirium.

\section{Limitation of the study}

One of the main limitations is the fact that we excluded patients with shorter duration of symptoms of delirium than 12 hours. It was recognized that it is important to differentiate between state after general anesthesia and real symptoms of delirium, which could be a mimicked state after general anesthesia. On the other side, many patients with short delirium, who had recovered rapidly were missed. This selection could influence the mean duration of delirium in the results. Another limitation was that sample size was not calculated prior to start of the study, so there is a risk of statistical error. The efficacy of the treatment stays was questionable due to the absence of blinded placebo group. The possibility to generalize these findings needs to be examined further in the following studies. The study was focused on the factors routinely measured or evaluated in ICU in Czech condition. However, there would be other factors, outside of routine, which could influence the duration of delirium, such as levels of neurotransmitters and hormones. Assessment of delirium severity is another problem. At the time of the realization of the study, the only standardized instrument was Riker SAS and RASS in Czech Republic. Therefore, it would be better to use CAM-ICU in the future studies, which was translated and standardized in the Czech Republic now.

Future studies are also needed to examine the factors, such as psychoactive drug use, invasive procedures, and sleep-wake cycle disruption, during the ICU stay and to examine their further contribution to baseline risk. ${ }^{70}$

\section{Conclusion}

Delirium is a frequent complication in ICU patients. It is an important condition associated with a number of significant issues and thus deserves its focused treatment, in addition to the management of actual medical conditions. Admission characteristics can be valuable markers for the duration of the delirium in these patients. The hyperactive type of delirium, hypotension, higher plasma potassium level, alcohol abuse in history, and antipsychotic medication in the SICU are associated with longer duration of delirium according to the data. Delirium brings with it an enormous morbidity and mortality burden - but it represents an incredibly complex condition, and the need to design methods and research to try and crack this complexity. Knowledge of these risk factors could lead to early corrections of metabolic abnormalities and may subsequently reduce the duration of delirium and its complications.

\section{Disclosure}

The authors declare no conflicts of interest in this work.

\section{References}

1. Aldemir M, Ozen S, Kara IH, Sir A, Bac B. Predisposing factors for delirium in the surgical intensive care unit. Crit Care. 2001;5(5):265-270.

2. Eastes LE. Alcohol withdrawal syndrome in trauma patients: a review. J Emerg Nurs. 2010;36(5):507-509. 
3. Maldonado JR. Neuropathogenesis of delirium: review of current etiologic theories and common pathways. Am J Geriatr Psychiatry. 2013; 21(12):1190-1222

4. Soysal P, Kaya D, Isik AT. Current concepts in the diagnosis, pathophysiology, and treatment of delirium: a European perspective. Curr Geriatr Rep. 2015;4(4):284-289.

5. Kähkönen S. Mechanisms of cardiovascular dysregulation during alcohol withdrawal. Prog Neuropsychopharmacol Biol Psychiatry. 2004;28(6):937-941.

6. Goodson CM, Clark BJ, Douglas IS. Predictors of severe alcohol withdrawal syndrome: a systematic review and meta-analysis. Alcohol Clin Exp Res. 2014;38(10):2664-2677.

7. Martin NJ, Stones MJ, Young JE, Bédard M. Development of delirium: a prospective cohort study in a community hospital. Int Psychogeriatr. 2000;12(1):117-127.

8. McNicoll L, Pisani MA, Zhang Y, Ely EW, Siegel MD, Inouye SK. Delirium in the intensive care unit: occurrence and clinical course in older patients. J Am Geriatr Soc. 2003;51(5):591-598.

9. Schmidt KJ, Doshi MR, Holzhausen JM, Natavio A, Cadiz M, Winegardner JE. Treatment of severe alcohol withdrawal. Ann Pharmacother. 2016;50(5):389-401.

10. Bergeron N, Dubois MJ, Dumont M, Dial S, Skrobik Y. Intensive care delirium screening checklist: evaluation of a new screening tool. Intensive Care Med. 2001;27(5):859-864

11. Ely EW, Margolin R, Francis J, et al. Evaluation of delirium in critically ill patients: validation of the Confusion Assessment Method for the Intensive Care Unit (CAM-ICU). Crit Care Med. 2001;29(7): 1370-1379.

12. Pisani MA, Araujo KL, Van Ness PH, Zhang Y, Ely EW, Inouye SK. A research algorithm to improve detection of delirium in the intensive care unit. Crit Care. 2006;10(4):R121.

13. Rudberg MA, Pompei P, Foreman MD, Ross RE, Cassel CK. The natural history of delirium in older hospitalized patients: a syndrome of heterogeneity. Age Ageing. 1997;26(3):169-174.

14. Mainerová B, Praško J, Látalová K, Šmoldasová J, Horáček R. Delirium tremens na klinice psychiatrie v Olomouci v letech 2005-2011 (in Czech). [Delirium tremens at the department of psychiatry in University Hospital Olomouc in years 2005-2011]. Čes a slov Psychiat. 2014; 110(3):127-132. Czech.

15. Salluh JI, Wang H, Schneider EB, et al. Outcome of delirium in critically ill patients: systematic review and meta-analysis. $B M J$. 2015;350:h2538.

16. Dubois MJ, Bergeron N, Dumont M, Dial S, Skrobik Y. Delirium in an intensive care unit: a study of risk factors. Intensive Care Med. 2001; 27(8):1297-1304.

17. Pandharipande P, Shintani A, Peterson J, et al. Lorazepam is an independent risk factor for transitioning to delirium in intensive care unit patients. Anesthesiology. 2006;104(1):21-26.

18. Ouimet S, Kavanagh BP, Gottfried SB, Skrobik Y. Incidence, risk factors and consequences of ICU delirium. Intensive Care Med. 2007;33(1): 66-73.

19. Kim DW, Kim HK, Bae EK, Park SH, Kim KK. Clinical predictors for delirium tremens in patients with alcohol withdrawal seizures. Am J Emerg Med. 2015;33(5):701-704.

20. Shu JE, Lin A, Chang G. Alcohol withdrawal treatment in the medically hospitalized patient: a pilot study assessing predictors for medical or psychiatric complications. Psychosomatics. 2015;56(5):547-555.

21. Zaal IJ, Devlin JW, Peelen LM, Slooter AJ. A systematic review of risk factors for delirium in the ICU. Crit Care Med. 2015;43(1):40-47.

22. Smulter N, Lingehall HC, Gustafson Y, Olofsson B, Engströma KG. Delirium after cardiac surgery: incidence and risk factors. Interact Cardiovasc Thorac Surg. 2013;17:790-798.

23. Ahmed S, Leurent B, Sampson EL. Risk factors for incident delirium among older people in acute hospital medical units: a systematic review and meta-analysis. Age Ageing. 2014;43:326-333.

24. Siddiqi N, Harrison JK, Clegg A, et al. Interventions for preventing delirium in hospitalized non-ICU patients. Cochrane Database Syst Rev. 2016;3:CD005563.
25. Francis J, Martin D, Kapoor WN. A prospective study of delirium in hospitalized elderly. JAMA. 1990;263(8):1097-1101.

26. Cole MG, Primeau FJ. Prognosis of delirium in elderly hospital patients. CMAJ. 1993;149(1):41-46.

27. Ely EW, Gautam S, Margolin R, et al. The impact of delirium in the intensive care unit on hospital length of stay. Intensive Care Med. 2001; 27(12):1892-1900.

28. McCusker J, Cole M, Dendukuri N, Belzile E, Primeau F. Delirium in older medical inpatients and subsequent cognitive and functional status: a prospective study. CMAJ. 2001;165(5):575-583.

29. Lin SM, Liu CY, Wang CH, et al. The impact of delirium on the survival of mechanically ventilated patients. Crit Care Med. 2004;32(11): 2254-2259.

30. Ely EW, Shintani A, Truman B, et al. Delirium as a predictor of mortality in mechanically ventilated patients in the intensive care unit. JAMA 2004;291(14):1753-1762.

31. Breitbart W, Gibson C, Tremblay A. The delirium experience: delirium recall and delirium-related distress in hospitalized patients with cancer, their spouses/caregivers, and their nurses. Psychosomatics. 2001;43(3): 183-194.

32. Cavallazzi R, Saad M, Marik P. Delirium in the ICU: an overview. Ann Intensive Care. 2012;2(1):49.

33. Page VJ, Ely EW, Gates S, et al. Effect of intravenous haloperidol on the duration of delirium and coma in critically ill patients (Hope-ICU): a randomized, double-blind, placebo-controlled trial. Lancet Respir Med. 2013;1(7):515-523.

34. Al-Qadheeb NS, Balk EM, Fraser GL, Skrobik Y, Riker RR, Kress JP. Randomized ICU trials do not demonstrate an association between interventions that reduce delirium duration and short-term mortality: a systematic review and meta-analysis. Crit Care Med. 2014;42(6):1442.

35. Pisani MA, Murphy TE, Araujo KLB, Slattum P, Van Ness PH, Inouye SK. Benzodiazepine and opioid use and the duration of ICU delirium in an older population. Crit Care Med. 2009;37(1):177-183.

36. Edlund A, Lundström M, Brännström B, Bucht G, Gustafson Y. Delirium before and after operation for femoral neck fracture. $J \mathrm{Am}$ Geriatr Soc. 2001;49(10):1335-1340.

37. Litaker D, Locala J, Franco K, Bronson DL, Tannous Z. Preoperative risk factors for postoperative delirium. Gen Hosp Psychiatry. 2001;23(2) 84-89.

38. Galanakis P, Bickel H, Gradinger R, Von Gumppenberg S, Förstl H. Acute confusional state in the elderly following hip surgery: incidence, risk factors, and complications. Int J Geriatr Psychiatry. 2001; 16(4):349-355.

39. Schneider F, Böhner H, Habel U, et al. Risk factors for postoperative delirium in vascular surgery. Gen Hosp Psychiatry. 2002;24(1):28-34.

40. Liptzin B, Laki A, Garb JL, Fingeroth R, Krushell R. Donepezil in the prevention and treatment of post-surgical delirium. Am J Geriatr Psychiatry. 2005;13(12):1100-1106.

41. Bellelli G, Mazzola P, Morandi A, et al. Duration of postoperative delirium is an independent predictor of 6-month mortality in older adults after hip fracture. J Am Geriatr Soc. 2014;62(7):1335-1340.

42. Neufeld KJ, Yue J, Robinson TN, Inouye SK, Needham DM. Antipsychotic medication for prevention and treatment of delirium in hospitalized adults: a systematic review and meta-analysis. J Am Geriatr Soc. 2016;64(4):705-714.

43. Olofsson SM, Weitzner MA, Valentine AD, Baile WF, Meyers CA. A retrospective study of the psychiatric management and outcome of delirium in the cancer patient. Support Care Cancer. 1996;4(5): $351-357$.

44. Koponen H, Stenbäck U, Mattila E, Soininen H, Reinikainen K, Riekkinen PJ. Delirium among elderly persons admitted to a psychiatric hospital: clinical course during the acute stage and one-year follow-up. Acta Psychiatr Scand. 1989;79(6):579-585.

45. Inouye SK, van Dyck CH, Alessi CA, Balkin S, Siegal AP, Horwitz RI. Clarifying confusion: the confusion assessment method. Ann Intern Med. 1990;113(12):941-948.

46. Someya T, Endo T, Hara T, Yagi G, Suzuki J. A survey on the drug therapy for delirium. Psychiatry Clin Neurosci. 2001;55(4):397-401. 
47. Ely EW, Stephens RK, Jackson JC, et al. Current opinions regarding the importance, diagnosis, and management of delirium in the intensive care unit: a survey of 912 healthcare professionals. Crit Care Med. 2004; 32(1):106-112.

48. Lucht M, Kuehn KU, Armbruster J, et al. Alcohol withdrawal treatment in intoxicated vs. non-intoxicated patients: a controlled open-label study with tiapride/carbamazepine, clomethiazole, and diazepam. Alcohol Alcohol. 2003;38(2):168-175.

49. Soyka M, Kranzler HR, Berlund M, Gorelick D, Hesselbrock V, Johnson BA. The WFSBP task force on treatment guidelines for substance use. World Federation of Societies of Biological Psychiatry (WFSBP) guidelines for biological treatment of substance use and related disorders, part 1: alcoholism. World J Biol Psychiatry. 2008; 9(1):6-23.

50. Boettger S, Jenewein J, Breitbart W. Haloperidol, risperidone, olanzapine and aripiprazole in the management of delirium: a comparison of efficacy, safety, and side effects. Palliat Support Care. 2015;13(04): 1079-1085.

51. Pattern SB, Williams JVA, Petcu R, Oldfield R. Delirium in psychiatric inpatients: a case-control study. Can J Psychiatry. 2001;46(2): $162-166$.

52. Gaudreau JD, Gagnon P, Roy MA, Harel F, Tremblay A. Association between psychoactive medications and delirium in hospitalized patients: a critical review. Psychosomatics. 2005;46(4):302-316.

53. Pisani MA, Murphy TE, Van Ness PH, Araujo KL, Inouye SK. Characteristics associated with delirium in older patients in a medical intensive care unit. Arch Intern Med. 2007;167(15):1629-1634.

54. Seitz DP, Sudeep SG, van Zyl LT. Antipsychotics in the treatment of delirium: a systematic review. J Clin Psychiatry. 2007;68(1):11-21.

55. Manos PJ, Wu R. The duration of delirium in medical and postoperative patients, referred for psychiatry consultation. Ann Clin Psychiatry. 1997;9(4):219-226.

56. Milbrandt EB, Kersten A, Kong L, et al. Haloperidol use is associated with lower hospital mortality in mechanically ventilated patients. Crit Care Med. 2005;33(1):226-229.

57. Kalisvaart KJ, de Jonghe JF, Bogaards MJ, et al. Haloperidol prophylaxis for elderly hip-surgery patients at risk for delirium: a randomized placebo-controlled study. J Am Geriatr Soc. 2005;53(10):1658-1666.
58. Liptzin B, Levkoff SE. An empirical study of delirium subtypes. Br J Psychiatry. 1992;161:843-845.

59. Meagher DJ, O'Hanlon D, O'Mahony E, Casey PR. The use of environmental strategies and psychotropic medications in the management of delirium. Br J Psychiatry. 1996;168(4):512-515.

60. Inouye SK, Viscoli CM, Horwitz RI, Hurst LD, Tinetti ME. A predictive model for delirium in hospitalized elderly medical patients based on admission characteristics. Ann Intern Med. 1993;119(6):474-481.

61. Marcantonio ER, Goldman L, Mangione CM, et al. A clinical prediction rule for delirium after elective noncardiac surgery. JAMA. 1994; 271(2):134-139.

62. Lynch EP, Lazor MA, Gellis JE, Orav J, Goldman L, Marcantonio ER. The impact of postoperative pain on the development of postoperative delirium. Anesth Analg. 1998;86(4):781-785.

63. Wilcox ME, Brummel NE, Archer K, Ely EW, Jackson JC, Hopkins RO. Cognitive dysfunction in ICU patients: risk factors, predictors, and rehabilitation interventions. Crit Care Med. 2013;41(9):S81-S98.

64. Zaal I, Devlin J, Slooter A. A systematic review of risk factors for delirium in the intensive care unit. Crit Care Med. 2013;41(12):A136.

65. O’Keeffe ST, Lavan JN. Predicting delirium in elderly patients: development and validation of a risk-stratification model. Age Ageing. 1996; 25(4):317-321

66. Kalisvaart KJ, Vreeswijk R, de Jonghe JF, van der Ploeg T, van Gool WA, Eikelenboom P. Risk factors and prediction of postoperative delirium in elderly hip surgery patients: implementation and validation of a medical risk factor model. J Am Geriatr Soc. 2006;54(5):817-822.

67. Inouye SK, Bogardus ST Jr, Charpentier PA, et al. A multicomponent intervention to prevent delirium in hospitalized older patients. $N$ Engl J Med. 1999;340(9):669-676.

68. Rivers E, Nguyen B, Havstad S, et al; Early Goal-Directed Therapy Collaborative Group. Early goal-directed therapy in the treatment of severe sepsis and septic shock. N Engl J Med. 2001;345(19):1368-1377.

69. Mainerova B, Prasko J, Latalova K, et al. Alcohol withdrawal delirium - diagnosis, course, and treatment. Biomed Pap Med Fac Univ Palacky Olomouc Czech Repub. 2015;159(1):44-52.

70. Kamdar BB, Niessen T, Colantuoni E, et al. Delirium transitions in the medical ICU: exploring the role of sleep quality and other factors. Crit Care Med. 2015;43(1):135.
Neuropsychiatric Disease and Treatment

\section{Publish your work in this journal}

Neuropsychiatric Disease and Treatment is an international, peerreviewed journal of clinical therapeutics and pharmacology focusing on concise rapid reporting of clinical or pre-clinical studies on a range of neuropsychiatric and neurological disorders. This journal is indexed on PubMed Central, the 'PsycINFO' database and CAS,

\section{Dovepress}

and is the official journal of The International Neuropsychiatric Association (INA). The manuscript management system is completely online and includes a very quick and fair peer-review system, which is all easy to use. Visit http://www.dovepress.com/testimonials.php to read real quotes from published authors. 